\title{
Kynurenine 3-monooxygenase is a critical regulator of renal ischemia-reperfusion injury
}

\author{
Xiaozhong Zheng ${ }^{1}$, Ailiang Zhang ${ }^{1}$, Margaret Binnie ${ }^{2}$, Kris McGuire², Scott P. Webster ${ }^{2}$, Jeremy Hughes ${ }^{1}$,
} Sarah E. M. Howie ${ }^{1}$ and Damian J. Mole (1)

\begin{abstract}
Acute kidney injury (AKI) following ischemia-reperfusion injury (IRI) has a high mortality and lacks specific therapies. Here, we report that mice lacking kynurenine 3-monooxygenase $(\mathrm{KMO})$ activity ( $K m \mathrm{O}^{\text {null }}$ mice) are protected against AKI after renal IRI. We show that KMO is highly expressed in the kidney and exerts major metabolic control over the biologically active kynurenine metabolites 3-hydroxykynurenine, kynurenic acid, and downstream metabolites. In experimental AKI induced by kidney IRI, Kmo null mice had preserved renal function, reduced renal tubular cell injury, and fewer infiltrating neutrophils compared with wild-type $\left(\mathrm{Kmo}^{\mathrm{wt}}\right)$ control mice. Together, these data confirm that flux through $\mathrm{KMO}$ contributes to $\mathrm{AKI}$ after IRI, and supports the rationale for $\mathrm{KMO}$ inhibition as a therapeutic strategy to protect against AKI during critical illness.
\end{abstract}

\section{Introduction}

In eukaryotes, the metabolic fate of the essential aminoacid tryptophan is conversion via the kynurenine pathway into a range of metabolites that includes kynurenic acid, 3hydroxykynurenine, and quinolinic acid. Enzymes involved in the metabolism of tryptophan along the kynurenine pathway are located throughout the body and brain, and are most abundant in the liver and kidney. The conversion of tryptophan to $N$-formylkynurenine (KYN) is catalyzed by tryptophan 2,3-dioxygenase (TDO) and indoleamine 2,3-dioxygenases (IDOs). The kynurenine pathway diverges at kynurenine into two distinct branches that are regulated by kynurenine aminotransferases (KATs) and kynurenine 3-monooxygenase (KMO), respectively (Fig. 1). KMO is the only route of 3-hydroxykynurenine production known to occur in humans. KMO localizes to the outer membrane of mitochondria, and is highly

\footnotetext{
Correspondence: Damian J. Mole (damian.mole@ed.ac.uk)

${ }^{1}$ Centre for Inflammation Research, University of Edinburgh, 47 Little France Crescent, Edinburgh EH16 4TJ, UK

${ }^{2}$ Centre for Cardiovascular Science, University of Edinburgh, 47 Little France Crescent, Edinburgh EH16 4TJ, UK
}

expressed in peripheral tissues, including liver and kidney ${ }^{1}$. KMO expression in mouse kidney is localized to the proximal tubule epithelial cells when measured by singlecell transcriptomics ${ }^{2}$ and KMO protein in humans is also localized to kidney tubule epithelial cells using immunohistochemistry ${ }^{3}$. 3-Hydroxykynurenine is injurious to several cell types ${ }^{4}$, causing tissue injury via oxidative stress, pathological cross-linking of proteins ${ }^{5}$, and inducing apoptotic cell death ${ }^{6,7}$. Kynurenine may also be metabolized to kynurenic acid by KATs and to anthranilic acid by kynureninase. Kynurenic acid is sedative ${ }^{8}$ and has been shown to be protective against cell injury in certain inflammatory situations ${ }^{9,10}$.

Renal ischemia-reperfusion injury (IRI) is a leading cause of acute kidney injury (AKI). AKI, as a component of multiple organ dysfunction syndrome (MODS), has a high mortality and lacks specific therapies. Renal IRI may occur as a result of primary decrease in blood flow, followed by reperfusion, for example, during abdominal aortic aneurysm repair or renal transplantation, or secondary to, and as part of a systemic inflammatory response, for example, during sepsis or severe acute 


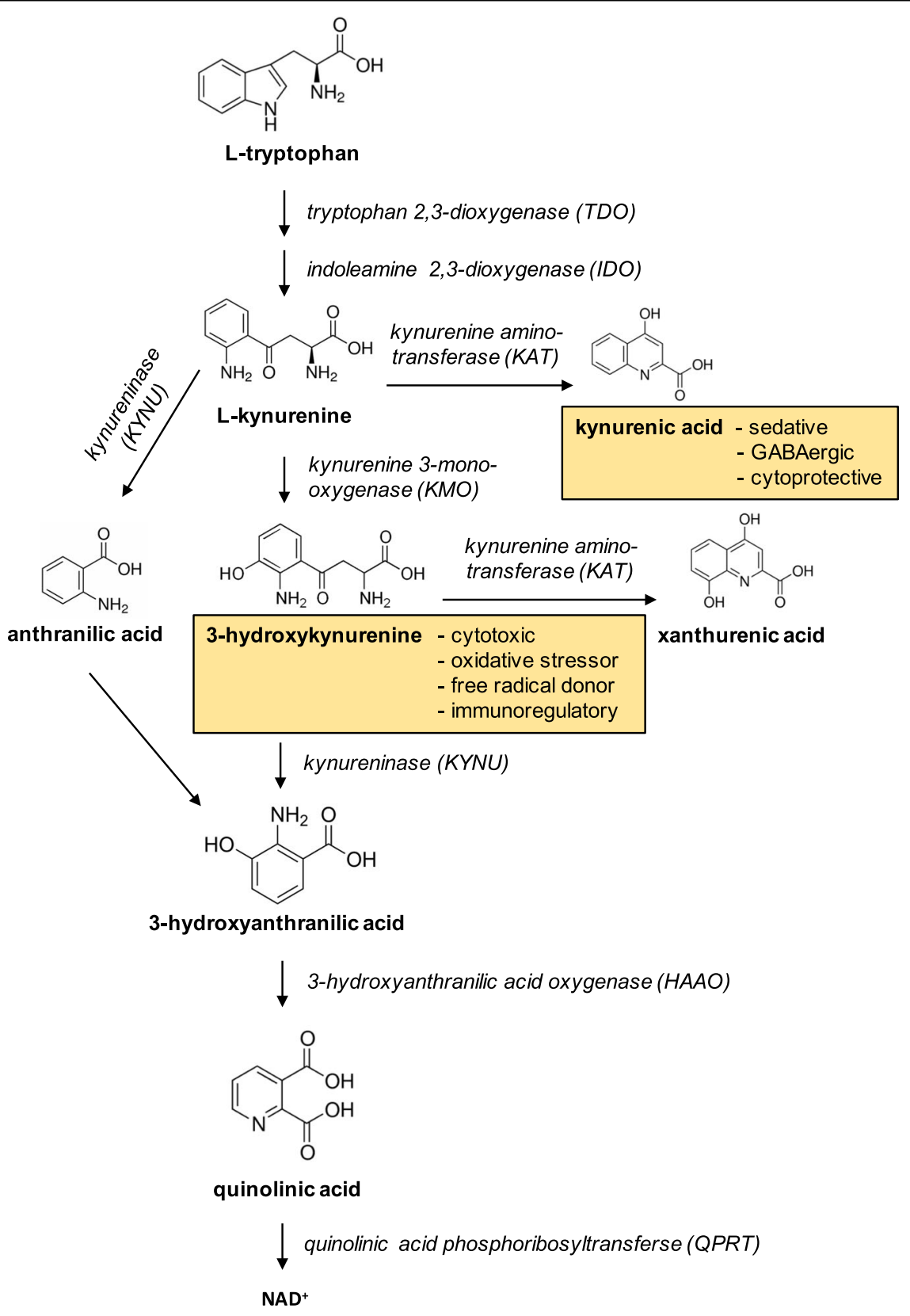

Fig. 1 Overview of the kynurenine pathway of tryptophan metabolism. 3-Hydroxykynurenine, the product of the gate-keeper enzyme kynurenine 3-monooxygenase (KMO), and kynurenic acid, one of the other branch metabolite are highlighted

pancreatitis $(\mathrm{AP})^{11}$. The exact mechanisms that drive AKI in systemic inflammation and MODS are not well understood, but are likely to stem from a combination of hypoperfusion-reperfusion (IRI) and metabolic toxicity. In the context of secondary $\mathrm{AKI}$, in experimental rodent models of AP-MODS, in which AKI is an important contributor, pharmacological inhibition of $\mathrm{KMO}$, and separately, transcriptional blockade of the Kmo gene, reduces 3-hydroxykynurenine formation and protects against AKI ${ }^{12-15}$. However, whether Kmo gene blockade protects against primary IRI-induced AKI is not known. Therefore, to further elucidate the role of renal KMO in protecting against experimental AKI, we tested whether mice lacking functional $\mathrm{KMO}$ are protected from experimental AKI induced by the direct insult of renal IRI.

\section{Materials and methods \\ Ethical considerations}

All experiments were performed after Research Ethics Committee and Veterinary review at The University of 
Edinburgh, and were conducted according to the United Kingdom Use of Animals (Scientific Procedures) Act 1986, under license PPL60/4250.

\section{Animals}

Embryonic stem cells on a C57BL/6N background were engineered to lack KMO activity by insertion of a polyA transcription "stop" motif before exon 5 of the Kmo gene $\left(K m o^{t m l a(K O M P) W t s i}\right)$ by the International Knockout Mouse Project (iKOMP). These mice were backcrossed with C57BL/6J mice to generate mice lacking KMO activity, hereafter referred to as $K m o^{\text {null }}$ mice as previously described $^{12}$. Control mice $\left(K m o^{\text {tmlc(KOMP)Wtsilflox(ex5) }}\right.$, with normal Kmo gene transcription and KMO activity with loxP-flanked exon 5 of Kmo but no cre-recombinase expression and therefore a wild-type phenotype, hereafter referred to as $K m o^{\mathrm{wt}}$ mice, were generated from the same founders as the $K m o^{\text {null }}$ strain. Genotyping of all mice was performed by polymerase chain reaction (PCR) using primers and a protocol published previously ${ }^{12}$. Male mice only were used. Mice were 10-15 weeks old and were housed under specific pathogen-free conditions in the Biomedical Research Resources Facility of the University of Edinburgh.

\section{Experimental IRI}

Experimental kidney IRI was induced as described previously ${ }^{16}$. Briefly, mice were given a general anesthetic using intraperitoneal ketamine and metomidate according to local dosage guidelines. Under aseptic conditions, a midline laparotomy and right nephrectomy were performed. The left renal pedicle was identified and occluded by atraumatic clamp for $22 \mathrm{~min}$. The duration of clamping was determined by our previous experience with this model using the same background mouse strain. Body temperature was maintained at $35^{\circ} \mathrm{C}$ using a homeostatically controlled blanket (Harvard Apparatus, Boston, MA). After reperfusion, the abdominal wall was sutured closed with 5-0 polypropylene and the skin closed with metal clips. Anesthesia was reversed with Antisedan. Fluid resuscitation with $1 \mathrm{~mL}$ of sterile $0.9 \% \mathrm{NaCl}$ was administered subcutaneously to the scruff after surgery. Shamoperated mice underwent general anesthesia, laparotomy, and unilateral nephrectomy, but no clamping of the left renal pedicle. The animals were singly housed and maintained in a $28^{\circ} \mathrm{C}$ warm box overnight to recover from surgery. After $24 \mathrm{~h}$, mice were humanely killed under terminal general anesthesia. Blood was collected into tubes containing EDTA (BD Biosciences). Urine was collected into sterile Eppendorf tubes. Whole kidneys were cut longitudinally and either snap frozen in liquid nitrogen for subsequent mRNA extraction or fixed in $10 \%$ neutral buffered formalin before embedding in paraffin for histological analysis.

\section{Assessment of renal function}

Plasma samples were prepared from whole blood by centrifugation at $1000 \times g$ for $5 \mathrm{~min}$ followed by aliquoting of the supernatant, freezing in dry ice and storage at $-80^{\circ} \mathrm{C}$ until analysis without freeze-thaw. Amylase, albumin, alanine aminotransferase, glucose, urea, and creatinine were analyzed by using commercial kits (Product codes are $17632 \mathrm{H}, 17600 \mathrm{H}, 17234 \mathrm{H}, 17630 \mathrm{H}$, $17629 \mathrm{H}$, and $17654 \mathrm{H}$, respectively. Alpha Laboratories Ltd, Eastleigh, UK) adapted for use on a Cobas Fara centrifugal analyzer (Roche Diagnostics Ltd, Welwyn Garden City, UK). Specifically, creatinine was determined using the creatininase/creatinase-specific enzymatic method. Urinary albumin excretion was expressed as albumin/creatinine ratio (ACR).

\section{Histology and digital image analysis}

Histological sections $(4 \mu \mathrm{m})$ of formalin-fixed paraffinembedded kidney tissue were de-waxed and taken through a decreasing series of graded alcohols to water. Hematoxylin and eosin (H\&E) staining was performed according to standard protocols. The H\&E-stained sections were scored in a blinded fashion for assessment of tubular necrosis in the outer medulla ${ }^{17}$. Ten representative random fields at a magnification of $\times 200$ per section for each sample were examined. The percentage of tubules in the corticomedullary junction that displayed cellular necrosis and a loss of brush border were counted.

To assess the extent of apoptotic cell death induced by IRI, we performed terminal deoxynucleotidyl transferase dUTP-mediated nick-end labeling (TUNEL) staining on paraffin-embedded kidney tissue sections using a commercially available kit (DeadEnd fluorometric TUNEL system; Promega, Madison, WI, USA). Briefly, formalinfixed sections of $4 \mu \mathrm{m}$ thickness were deparaffinized, hydrated, and incubated with $20 \mu \mathrm{g} / \mathrm{mL}$ proteinase $\mathrm{K}$ to strip proteins from the nuclei. Fragmented DNA was then identified by the incorporation of fluorescein-12-dUTP during an incubation step with terminal deoxynucleotidyl transferase at $37^{\circ} \mathrm{C}$ for $1 \mathrm{~h}$. Sections were stained by immersing the slides in $40 \mathrm{~mL}$ of propidium iodide solution freshly diluted to $1 \mu \mathrm{g} / \mathrm{mL}$ in phosphate buffered saline for $15 \mathrm{~min}$. Microscopic images were acquired at $\times$ 10 magnification by using a Leica DC350F digital camera system equipped with Nikon Eclipse E800 Fluorescence microscope and Image-Pro Plus image analysis software (Media Cybernetics). Apoptotic cells (TUNEL-positive cells) were quantitatively assessed at $\times 100$ magnification for 13 fields of tubular areas in a blinded manner using ImageJ as previously described ${ }^{12}$.

We also performed cleaved caspase-3 immunohistochemistry from paraffin sections to detect renal apoptosis. Renal macrophages were identified by immunostaining for the tissue macrophage marker F4/80. Myeloperoxidase 
(MPO)-positive cells were quantified in post-ischemic kidney sections as an index of neutrophil infiltration. The following primary antibodies were used: cleaved caspase-3 (ASP175) antibody with cat no. 9661 (Cell Signaling, Danvers, MA, USA) at a dilution of 1:300, anti-mouse F4/80 monoclonal antibody (clone BM8) \#14-4801 (eBioscience, Hatfield, UK) at 1:100 dilution, and rabbit anti-MPO polyclonal antibody \#1224 (Merck Millipore Corporation) at 1:1000 dilution. Visualization was with diaminobenzoate (DAB) according to standard protocols. Type-specific control antibodies were used to distinguish background staining. Immunohistochemistry slides were scanned in their entirety using an AxioScan.Z1 system (Zeiss microscopy $\mathrm{GmbH}$, Oberkochen, Germany) and stored as.czi files before export as reduced-size.jpg files into ImageJ. Enumeration of caspase- $3^{+}, \mathrm{F} 4 / 80^{+}$, and $\mathrm{MPO}^{+}$cells was done using ImageJ as previously described ${ }^{12}$, and expressed as positive cells per million pixels.

\section{RNA extraction and real-time PCR}

Total RNA was extracted from kidney tissue using an RNeasy Mini kit (Qiagen). In all, $1 \mu \mathrm{g}$ of total RNA was used for first-strand complementary DNA (cDNA) synthesis using a QuantiTect Reverse Transcription Kit (Qiagen). Expression of genes was determined by realtime PCR. Specific TaqMan primers and probes for Kmo, kynureninase (Kynu), Kat2, 3-hydroxyanthranilic acid oxidase (Haao), interleukin-6 (Il6), tumor necrosis factor $\alpha$ (Tnfa), chemokine (C-X-C motif) ligand 1 (Cxcl1), and ligand 2 ( $C x c l 2)$ were purchased from Life Biotechnologies. 18S ribosomal RNA was used as a reference gene. Amplification of cDNA samples was carried out using TaqMan $^{\circledast}$ Fast Universal PCR Master Mix (AB Applied Biosystem) under the following conditions: 1-min denaturation at $95^{\circ} \mathrm{C}, 45$ cycles of $15 \mathrm{~s}$ at $95^{\circ} \mathrm{C}$, and $30 \mathrm{~s}$ at $60^{\circ} \mathrm{C}$. Thermal cycling and fluorescence detection were conducted in a StepOne real-time PCR system (Applied Biosystems). All reactions were carried out in triplicate and the cycle threshold $(\mathrm{Ct})$ numbers of the target gene and reference gene in each sample were obtained. The mRNA levels of the target gene are presented as relative quantification $(R Q)$ values.

\section{Liquid chromatography-tandem mass spectrometry (LC- MS/MS) analysis of kynurenine pathway metabolites}

Samples of plasma were diluted at a ratio of $2: 5$ in $5 \mathrm{mM}$ ammonium formate containing $0.1 \%$ trifluoracetic acid. Protein was precipitated by the addition of ice-cold $100 \%$ trichloroacetic acid to samples, followed by incubation for $30 \mathrm{~min}$ at $4{ }^{\circ} \mathrm{C}$ and centrifugation to obtain the supernatant. Serial dilutions of each metabolite were prepared over appropriate concentration ranges to prepare a calibration curve to permit quantitation. In all, $10 \mu \mathrm{L}$ volumes of each sample were injected onto a Waters Select HSS
$\mathrm{XP}$ column $(30 \mathrm{~mm} \times 100 \mathrm{~mm}, 2.5 \mu \mathrm{m}$, Waters Corp, Elstree, Herts) using a Waters Acquity UPLC autosampler, coupled to an ABSciex QTRAP 5500 mass analyzer. The flow rate was $0.35 \mathrm{~mL} / \mathrm{min}$ at $25^{\circ} \mathrm{C}$. Separation was carried out using a water:methanol gradient (both containing $0.1 \%$ formic acid). Conditions were 50:50 water:methanol to $40: 60$ over $60 \mathrm{~s}, 40: 60$ to $35: 65$ over $180 \mathrm{~s}$, hold 35:65 for $110 \mathrm{~s}, 35: 65$ to 50:50 over $10 \mathrm{~s}$, and re-equilibration at 50:50 for $200 \mathrm{~s}$. The total run time was $10 \mathrm{~min}$. The mass spectrometer was operated in positive electrospray mode. The transitions for the protonated analytes were kynurenine, $\mathrm{m} / \mathrm{z}$ 209-192; 3-hydroxykynurenine, m/z 225-202; tryptophan, m/z 205-188; kynurenic acid, m/z 190-144; and 3-hydroxyanthranilic acid, $\mathrm{m} / \mathrm{z}$ 154-136. Collision energies were $29,15,11,31$, and $33 \mathrm{eV}$ respectively. Data were acquired and processed using Analyst quantitation software (ABI Sciex).

\section{Tissue KMO enzyme activity assay}

KMO enzyme activity assay in kidney tissue was determined as follows: $50-100 \mathrm{mg}$ kidney tissue sample in $1 \mathrm{~mL}$ cold $0.32 \mu \mathrm{M}$ sucrose solution was homogenized and then centrifuged at $1500 \mathrm{rpm}$ for $5 \mathrm{~min}$. Total protein concentration in the homogenate was determined using a Pierce BCA protein kit and adjusted to $2 \mathrm{mg} / \mathrm{mL}$ with $0.32 \mu \mathrm{M}$ sucrose. In all, $10 \mu \mathrm{L}$ of homogenate was added to $90 \mu \mathrm{L}$ of master mix containing $200 \mu \mathrm{M}$ kynurenine, $800 \mu \mathrm{M}$ NADP, 3 mM G-6P, 1 unit of G6PD, 4 mM MgCI, and $2 \mathrm{mM}$ HEPES with $\mathrm{pH} 7.4$ in a well of a 96-well v-bottomed plate. The mix was incubated for $2 \mathrm{~h}$ at $37^{\circ} \mathrm{C}$ with $250 \mathrm{rpm}$ on an orbital shaker. In total, $500 \mu \mathrm{L}$ of $100 \%$ acetonitrile, $250 \mathrm{ng} / \mathrm{mL}$ d5-tryptophan was added to each well after the incubation and the plate was centrifuged at $4000 \mathrm{rpm}$ for $10 \mathrm{~min}$. The supernatant was removed and dried under nitrogen at $65^{\circ} \mathrm{C}$, and then resuspended in $100 \mu \mathrm{L}$ of mobile phase (30:70 methanol: water containing $0.1 \%$ formic acids) for LC-MS analysis. Separation was carried out on a $5 \mu \mathrm{M}, 100 \times 4.6 \mathrm{~mm}$ Allure Biphenyl HPLC column using a methanol/water gradient at $50^{\circ} \mathrm{C}$ with a flow rate of $500 \mu \mathrm{L} / \mathrm{min}$. Typical retention times were $2.3 \mathrm{~min}$ for $3 \mathrm{HK}$ and $2.6 \mathrm{~min}$ for $\mathrm{d} 5$ tryptophan. The product ions of $3 \mathrm{HK}$ (tube lens $=75$ ) and d5-tryptophan (internal standards, tube lens $=55$ ) are detected. The peak area ratio (3HK area/d5-tryptophan area) for each sample is calculated and the amount of $3 \mathrm{HK}$ is determined from a standard curve of known $3 \mathrm{HK}$ concentrations $(50,100,250,500,750,1000,1500$, $2000 \mathrm{ng} / \mathrm{mL}$ ). 3-Hydroxykynurenine was detected using LC-MS/MS.

\section{Experimental design and statistical analysis}

A simple $2 \times 2$ factorial design was used to compare experimental IRI versus a sham procedure in $K m o^{\text {null }}$ and $K m o^{\mathrm{wt}}$ mouse strains. Group sizes were determined 
by a prospective power calculation using G-power ${ }^{\mathrm{n}} 18$ using input parameters from previous IRI experiments using the same IRI method and background mouse strain. A detectable effect size of 0.80 with power $1-\beta=$ 0.80 and significance, $\alpha=0.05$, resulted in group sizes of $n=6$ mice per group. All data are expressed as mean \pm SEM. All data were subjected to a one-sample Kolmogorov-Smirnov test to check whether data adhered to a normal distribution. Normally distributed data were analyzed by one-way analysis of variance (ANOVA) followed by Tukey's multiple comparison test. Data that did not follow a normal distribution were analyzed by Kruskal-Wallis test. All statistical analyses were performed using GraphPad ${ }^{\mathrm{mm}}$ Prism version 6.0d for Macintosh (GraphPad Software, San Diego, CA).

\section{Results}

$\mathrm{Kmo}^{\text {null }}$ mice are protected against AKI after renal IRI

To determine whether absent KMO activity affected the severity of AKI after IRI, we compared the effect of experimental IRI in mice. Mice on a C57BL/6 background engineered to lack $\mathrm{KMO}$ activity by insertion of a polyA transcription "stop" motif before exon 5 of the Kmo gene $\left(K m o^{t m 1 a(K O M P) W t s i}\right)$, hereafter referred to as $K m o^{\text {null }}$ mice, were generated and maintained in our laboratory as previously described ${ }^{12}$. Control mice $\left(K m o^{t m 1 c(K O M P) W t s i f f l o x(e x 5)}\right)$, with normal Kmo gene transcription and KMO activity with loxP-flanked exon 5 of Kmo but no cre-recombinase expression and therefore a wild-type phenotype, hereafter referred to as $K m o^{\mathrm{wt}}$ mice, were generated from the same founders as the $K m o^{\text {null }}$ strain. We have previously shown that KMO enzyme catalytic activity in these mice closely correlates with gene expression at mRNA level in both mouse strains and in multiple tissues ${ }^{12} . K m o^{\text {null }}$ mice were protected against the effects of renal IRI, experiencing less severe AKI, demonstrated by a lower plasma creatinine and less tubular damage than $K m o^{\text {wt }}$ control mice (Fig. 2). The experimental model of IRI was effective at inducing severe AKI, because IRI caused an elevated plasma creatinine to $190.5 \pm 26.3 \mu \mathrm{mol} / \mathrm{L}$ at $24 \mathrm{~h}$ after IRI in $K m o^{\text {wt }}$ mice, compared with a plasma creatinine of $23.7 \pm 5.5 \mu \mathrm{mol} / \mathrm{L}$ at the equivalent time after sham operation in $K m o^{\mathrm{wt}}$ mice. $K m o^{\text {null }}$ mice had a lower plasma creatinine $24 \mathrm{~h}$ after IRI $(111.2 \pm 21.3 \mu \mathrm{mol} / \mathrm{l})$ compared with the equivalent value in $K m o^{\text {wt }}$ control mice. This difference was statistically significant $(P<$ 0.05) (Fig. 2a) with a magnitude that is biologically relevant. Renal IRI also significantly elevated the urinary ACR to $22,999 \pm 7747 \mathrm{mg} / \mathrm{g}$ at $24 \mathrm{~h}$ after IRI in $K m o^{\mathrm{wt}}$ mice, compared with an ACR of $174 \pm 50 \mathrm{mg} / \mathrm{g}$ at the equivalent time after sham operation in $K m o^{\text {wt }}$ mice $(P<0.01$, Fig. $2 \mathrm{~b}$ and Supplementary Figures $1 \mathrm{a}$ and $1 \mathrm{~b})$.
Urinary ACR was profoundly increased after IRI both in $K m o^{\mathrm{wt}}$ and $K m o^{\text {null }}$, confirming AKI, but the magnitude of this elevation in $K m o^{\text {null }}$ is smaller than that in $K m o^{\text {wt }}$ mice although this difference is not statistically significant $(P>0.999$, Fig. 2b). Because a previous report of a different strain of KMO-deficient mice ${ }^{19}$ reported proteinuria in unstressed KMO-deficient mice, we measured urine and plasma albumin concentrations (Supplementary Figure 1a and 1c). Urine albumin concentrations were not different between sham-operated $K m o^{\text {null }}$ and $K m o^{\text {wt }}$ mice, and not higher in $K m o^{\text {null }}$ mice.

When histological tubular damage was assessed, Kmonull mice were protected from structural AKI after IRI, congruent with the functional protection indicated by the plasma creatinine concentrations. $K m o^{\text {wt }}$ mice sustained severe tubular damage after IRI, evidenced by widespread tubular necrosis, loss of the brush border, cast formation, and tubular dilatation within the outer stripe of the outer medulla (Fig. 2c). On histological examination, kidneys from $K m o^{\text {null }}$ mice showed significantly less tubular damage after IRI compared with equivalent tissue sections from $K m o^{\text {wt }}$ mice. Kidneys from sham-operated mice from either $K m o^{\text {wt }}$ or $K m o^{\text {null }}$ strain incurred no visible tubular injury on histological assessment. Quantification of tissue injury, obtained by counting necrotic tubules expressed as a percentage of all tubules, was significantly lower in $K m o^{\text {null }}$ IRI mice $(41.3 \pm 4.0 \%)$ than $K m o^{\text {wt }}$ IRI mice $(60.8 \pm 2.3 \%)(P<0.01$, Fig. $2 d)$. Together, these data clearly show that absent KMO activity in kidney tissue leads to a less severe functional and histological phenotype in AKI following experimental IRI.

\section{Tubular epithelial cell apoptosis is reduced in the kidney of $\mathrm{Kmo}^{\text {null }}$ mice following IRI}

Because therapeutic $\mathrm{KMO}$ inhibition protects against renal tubular cell apoptosis in AKI during experimental $\mathrm{AP}$ in rats, and because the KMO product 3-hydroxykynurenine induces apoptosis of cells in vitro, we examined the extent of tubular cell apoptosis. We labeled and enumerated apoptotic renal tubular cells using the TUNEL assay. There was no difference in the baseline apoptotic cell count in renal tubules in $K m o^{\text {wt }}$ and $K m o^{\text {null }}$ mice. Experimental IRI was a powerful inducer of apoptosis in renal tubular cells, causing substantial tubular epithelial cell apoptosis detectable at $24 \mathrm{~h}$ after IRI (Fig. 3a). Importantly, although $K m o^{\text {null }}$ mice sustained a degree of renal tubular cell apoptosis, the number of TUNEL-positive apoptotic renal tubular cells was significantly lower in $K m o^{\text {null }}$ mice with IRI $(19.8 \pm$ $4.5 /$ field $)$ than in $K m o^{\text {wt }}$ control mice $(49.9 \pm 11.6 /$ field $)$ $(P<0.05$, Fig. $3 b)$. Furthermore, immunohistochemistry using an antibody to cleaved caspase- 3 corroborated the result obtained by TUNEL staining (Figs. 3c, d). 


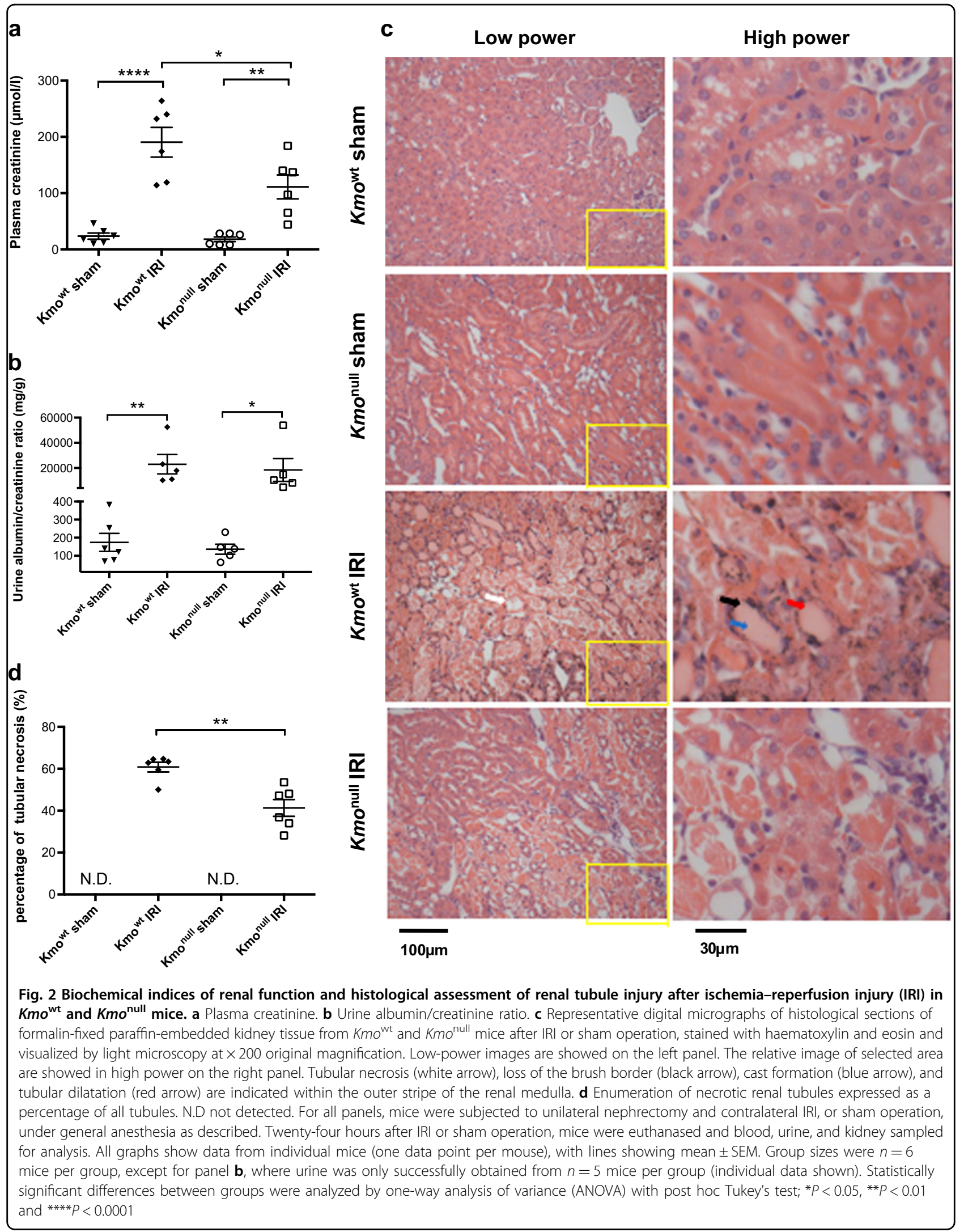




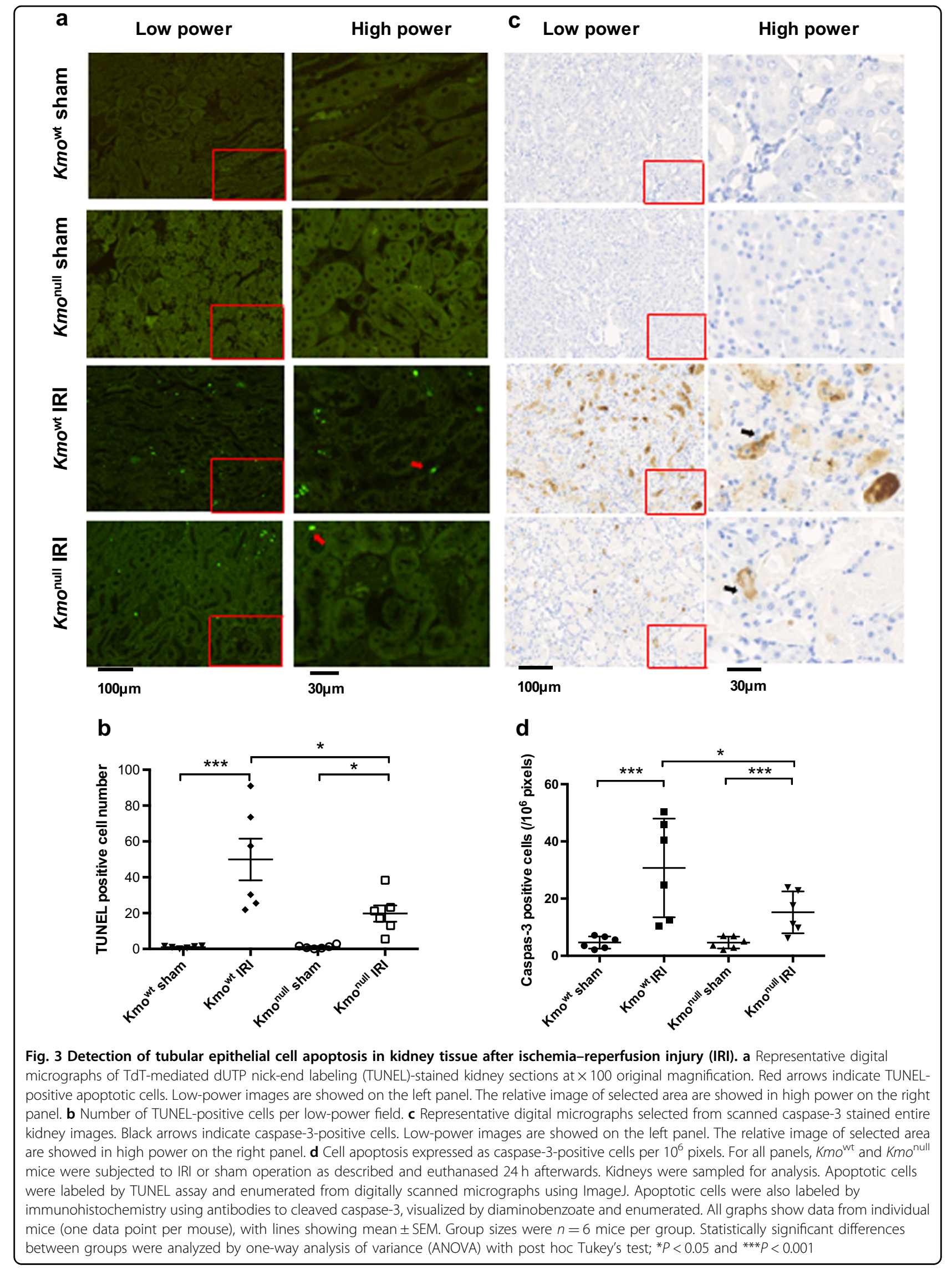




\section{KMO deletion inhibits neutrophil infiltration in the kidney following IRI}

AKI incorporates an element of acute inflammation. Therefore, we directly measured neutrophil accumulation in the kidney following IRI by immunohistochemical staining for $\mathrm{MPO}$ and enumeration of $\mathrm{MPO}^{+}$cells. A clearly measurable influx of $\mathrm{MPO}^{+}$neutrophils was identified on sections of kidney tissue in both $K m o^{\mathrm{wt}}$ and $K m o^{\text {null }}$ mice, $24 \mathrm{~h}$ after IRI, compared with very low numbers of $\mathrm{MPO}^{+}$cells in kidneys of sham-operated animals (Fig. 4a). Using quantitative analysis, we detected a lower number of accumulated neutrophils in the kidneys of $K m o^{\text {null }}$ mice $\left(25.2 \pm 4.5 / 10^{6}\right.$ pixels $)$ compared with $K m o^{\text {wt }}$ mice after IRI $\left(43.4 \pm 7.1 / 10^{6}\right.$ pixels $)$, and this difference was statistically significant $(P<0.05$, Fig. $4 \mathrm{~b})$. We also examined monocyte-derived macrophage accumulation after IRI by F4/80 immunohistochemistry (Fig. 4c). There was no significant infiltrate of cells positive for the mouse monocyte marker F4/80 in the kidney at $24 \mathrm{~h}$ after renal IRI in either $K m o^{\text {null }}$ mice $(17.0 \pm 1.2 /$ $10^{6}$ pixels) or $K m o^{\mathrm{wt}}$ mice $\left(18.2 \pm 2.8 / 10^{6}\right.$ pixels) (Fig. $\left.4 \mathrm{~d}\right)$.

\section{Renal IRI downregulates kynurenine pathway enzyme mRNA expression and upregulates interleukin- 6 and tumor necrosis factor-a mRNA expression}

Next, we asked whether IRI affected expression of kynurenine pathway enzymes, specifically Kmo, kynureninase $(K y n u)$, Kat2, 3-hydroxyanthranilic acid oxygenase (Haao), and Quinolinate phosphoribosyltransferase (Qprt) in kidney tissue. Using real-time PCR, we detected a profound and statistically significant decrease in Kmo mRNA expression in kidney tissue after IRI in $K m o^{\text {wt }}$ mice compared with baseline expression levels in shamoperated $K m o^{\mathrm{wt}}$ mice. There was no detectable Kmo mRNA expression in kidneys from $K m o^{\text {null }}$ mice, in keeping with the expected genotype and with our previous experience with this mouse strain (Fig. 5a). Interestingly, IRI caused a reduction in mRNA expression in both $K m o^{\mathrm{wt}}$ and $K m o^{\text {null }}$ mouse strains for Kynu, Kat2, Haao, and Qprt when compared with sham-operated mice of both transgenic strains. There was no strain-specific difference in the expression of Kynu, Kat2, Haao, and Qprt mRNA attributable to Kmo gene deletion in $K m o^{\text {null }}$ mice (Figs. 5b, c, d and supplementary Figure 2). The observed reduction in kynurenine pathway enzyme mRNA expression cannot be explained by experimental artifact, because quantification of mRNA expression of the proinflammatory cytokines interleukin-6 (IL-6) and tumor necrosis factor- $\alpha$ (TNF $\alpha)$ in the same cDNA preparations used for kynurenine pathway transcripts was significantly upregulated following IRI, and equally so in $K m o^{\mathrm{wt}}$ and $K m o^{\text {null }}$ mouse strains. Sham-operated mouse kidneys from both $K m o^{\text {wt }}$ and $K m o^{\text {null }}$ strains had very low expression of IL- 6 and TNF $\alpha$ mRNA. Mice subjected to
IRI demonstrated strong upregulation of IL- 6 and TNF $\alpha$ compared with sham-operated mice: IL-6 mRNA expression in the IRI kidney increased 173-fold in $\mathrm{Kmo}^{\mathrm{wt}}$ mice and 97.3-fold in $K m o^{\text {null }}$ mice, respectively (Fig. 5e); TNF $\alpha$ mRNA expression in the IRI kidney increased 3.9-fold in $K m o^{\text {wt }}$ mice and 2.1-fold in $K m o^{\text {null }}$ mice (Fig. 5f). The difference in IL-6 and TNF $\alpha$ mRNA upregulation in IRI was not statistically significant between $K m o^{\text {wt }}$ mice and $K m o^{\text {null }}$ mice. We also measured chemokine (C-X-C motif) ligand 1 ( $\mathrm{Cxcl1}$ ) and ligand 2 $(\mathrm{Cxcl} 2)$ mRNA levels in kidney tissue because these regulate the recruitment and infiltration of polymorphonuclear cells (PMN). Cxcl1 and Cxcl2 mRNA expression in IRI kidney tissue was significantly increased in $\mathrm{Kmo}^{\mathrm{wt}}$ mice. Cxcl2 mRNA level in $K m o^{\text {null }}$ mice was lower compared with $K m o^{\text {wt }}$ mice after IRI; this difference was statistically significant $(P<0.001)$, and congruent with the observation of a reduced neutrophil infiltrate. However, there was no difference between Cxcl1 mRNA levels in IRI kidney tissue from $K m o^{\text {wt }}$ mice and $K m o^{\text {null }}$ mice (Figs. 5g, h). Together, these data show that renal IRI drives a downregulation of kynurenine pathway enzyme mRNA expression, or potentially reflects loss of tubular cells through necrosis, independent of the functionality of $K m o$, and simultaneously upregulates pro-inflammatory cytokine expression.

\section{Kynurenine metabolite changes in experimental IRI in mice}

The metabolic product of KMO, 3-hydroxykynurenine, is injurious to cells and tissues. Because $K m o^{\text {null }}$ mice are unable to form 3-hydroxykynurenine and are also protected from AKI, it was important to confirm absent 3-hydroxykynurenine in plasma and kidney tissue after IRI. Furthermore, because the biochemical phenotype of $K m o^{\text {null }}$ mice is a diversion of kynurenine metabolism to kynurenic acid, and because we had observed that IRI downregulates kynurenine pathway enzyme mRNA expression, we measured kynurenine metabolite concentrations in plasma and tissue (Fig. 6). In sham-operated animals, we observed the plasma biochemical phenotype expected of $K m o^{\text {null }}$ mice, namely reduced (or absent) 3-hydroxykynurenine levels, reduced 3-hydroxyanthranilic acid levels, an upstream backlog of kynurenine, and a metabolic diversion of kynurenine to kynurenic acid. Tryptophan concentrations were not different between sham-operated $K m o^{\text {wt }}$ and $K m o^{\text {null }}$ mice. After IRI, the kynurenine pathway biochemical phenotype showed intriguing changes: plasma tryptophan was depleted. Tryptophan concentration in $K m o^{\text {null }}$ mice was significantly lower in the IRI group $(5501 \pm 999 \mathrm{ng} / \mathrm{mL})$ than in sham-operated group $(9411.0 \pm 588.2 \mathrm{ng} / \mathrm{mL})(P<$ 0.01). Tryptophan concentration in $K m o^{\mathrm{wt}}$ mice was also significantly lower in the IRI group $(3232 \pm 98.6 \mathrm{ng} / \mathrm{mL})$ than in sham-operated group $(8560 \pm 893.5 \mathrm{ng} / \mathrm{mL})$ 


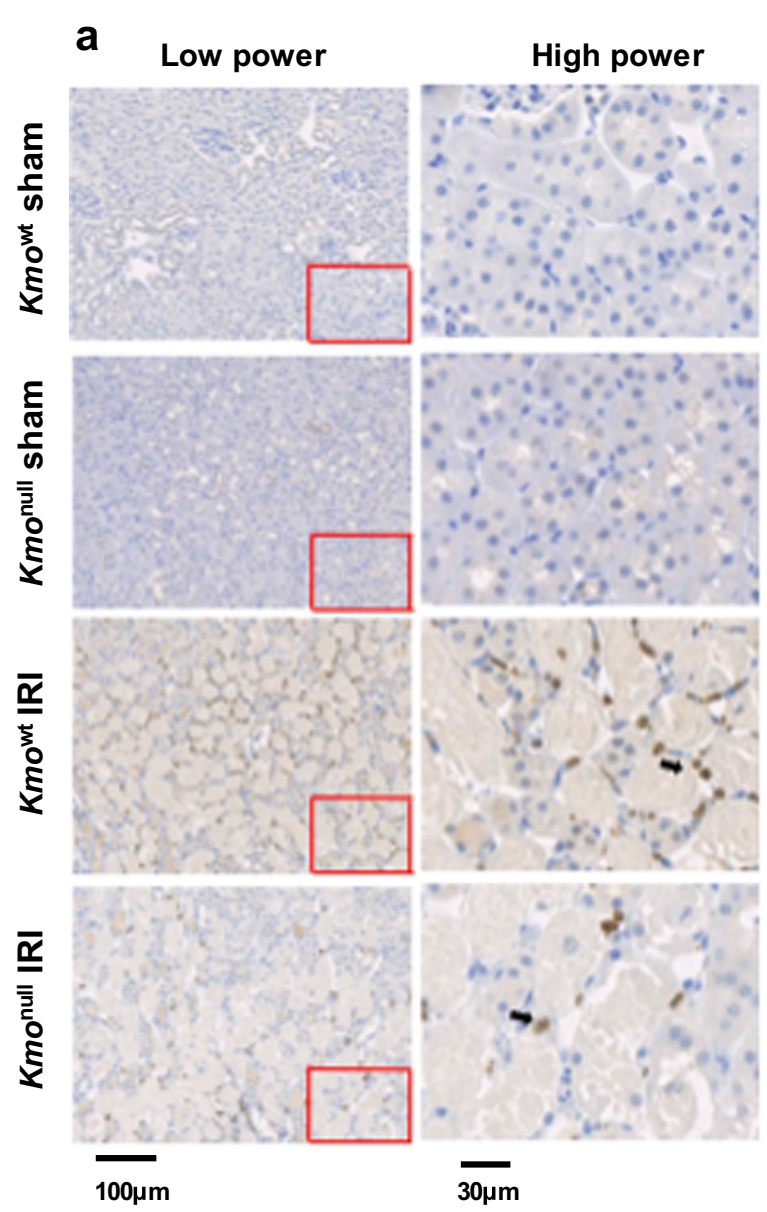

\section{Low power High power}
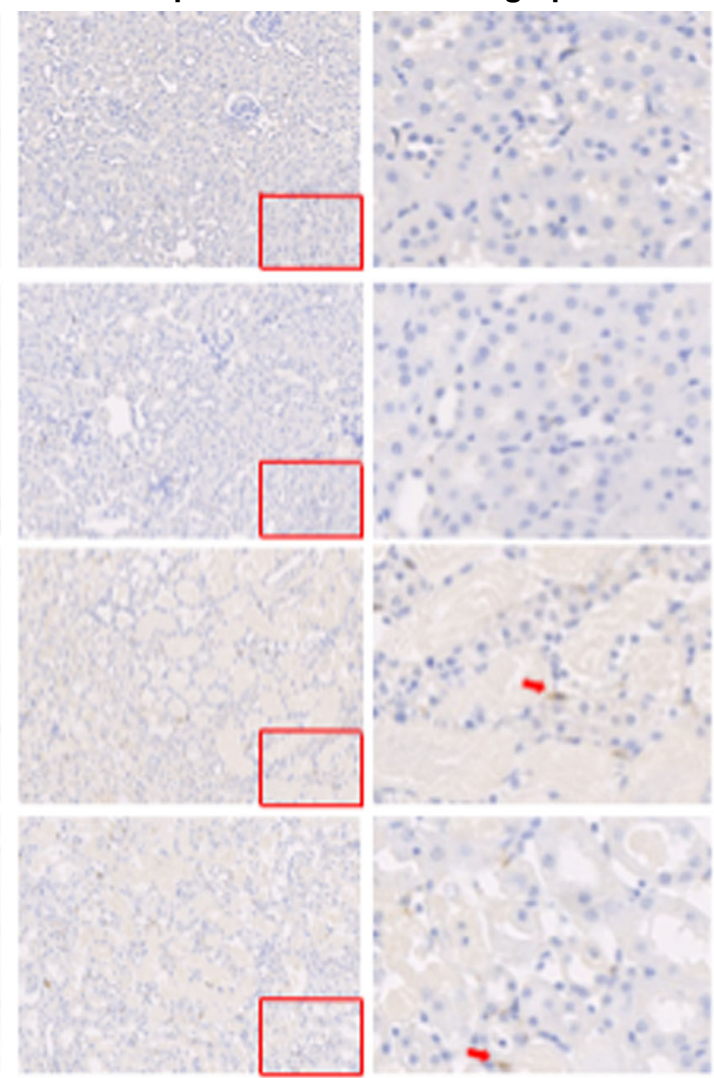

$\overline{100 \mu \mathrm{m}}$

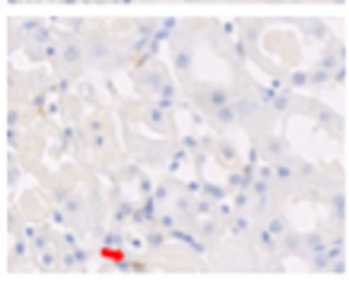

$100 \mu \mathrm{m}$

$30 \mu \mathrm{m}$

d

b
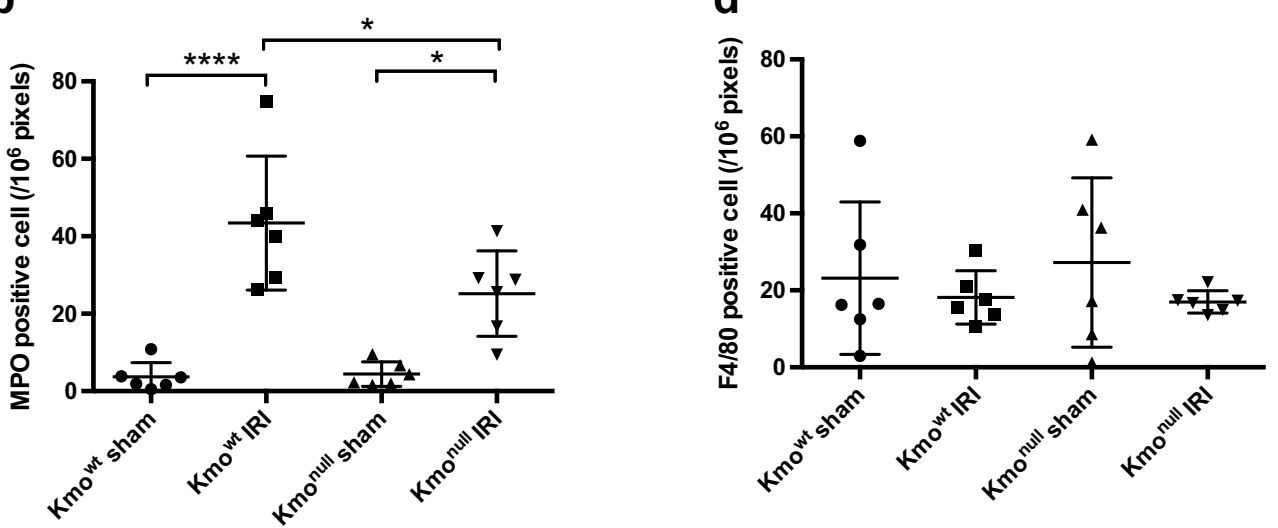

Fig. 4 Neutrophil infiltration and monocyte-derived macrophage accumulation in kidney tissue after ischemia-reperfusion injury (IRI). a Representative digital micrographs selected from scanned myeloperoxidase (MPO)-stained entire kidney images. Black arrows indicate $\mathrm{MPO}^{+}$cells. Low-power images are showed on the left panel. The relative image of selected area are showed in high power on the right panel. $\mathbf{b} \mathrm{MPO}^{+}$ neutrophil infiltration, expressed as $\mathrm{MPO}^{+}$cells per $10^{6}$ pixels. c Representative digital micrographs selected from scanned F4/80-stained entire kidney images. Red arrows indicate $\mathrm{MPO}^{+}$cells. Low-power images are showed on the left panel. The relative image of selected area are showed in high power on the right panel. $\mathbf{d ~ F} 4 / 80^{+}$monocyte-derived macrophage accumulation, expressed as $\mathrm{F} 4 / 80^{+}$cells per $10^{6}$ pixels. For all panels, Kmo ${ }^{\mathrm{wt}}$ and $K m O^{\text {null }}$ mice were subjected to IRI or sham operation as described and euthanased $24 \mathrm{~h}$ afterwards. Kidneys were sampled for analysis. Neutrophils and monocyte-derived macrophages were labeled by immunohistochemistry using antibodies to myeloperoxidase (MPO) and F4/80, respectively, visualized by diaminobenzoate and enumerated. All graphs show data from individual mice (one data point per mouse), with lines showing mean \pm SEM. Group sizes were $n=6$ mice per group. Statistically significant differences between groups were analyzed by one-way analysis of variance (ANOVA) with post hoc Tukey's test; ${ }^{*} P<0.05$ and ${ }^{* * *} P<0.0001$ 

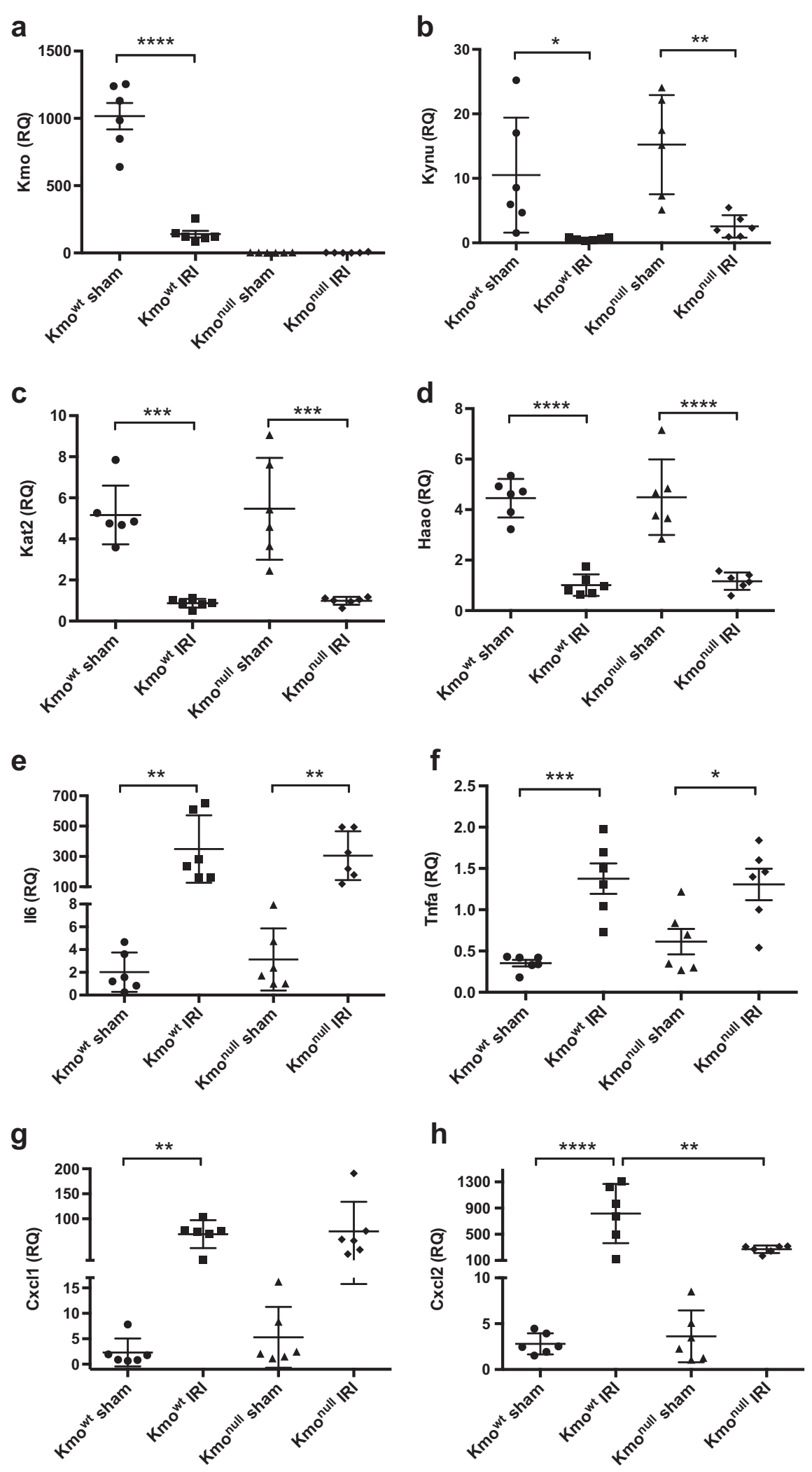

Fig. 5 (See legend on next page.) 
(see figure on previous page)

Fig. 5 mRNA expression of kynurenine pathway enzymes and pro-inflammatory cytokines in kidney tissue after ischemia-reperfusion injury (IRI). a Kynurenine 3-monoxygenase, Kmo; b kynureninase, Kynu; c kynurenine aminotransferase, Kat2; d 3-hydroxyanthranilic acid oxidase, Haao; e interleukin-6, II6; f tumor necrosis factor a, Tnfa. $\mathbf{g}$ chemokine (C-X-C motif) ligand 1, CXCl1; h chemokine (C-X-C motif) ligand 2, CXCl2. For all panels, $K \mathrm{KO}^{\mathrm{wt}}$ and $\mathrm{Kmo}^{\text {null }}$ mice were subjected to IRI or sham operation and euthanased $24 \mathrm{~h}$ afterwards. Kidney tissue was sampled, snap frozen in liquid nitrogen, and RNA subsequently extracted for analysis by real-time PCR as described. mRNA levels of the target gene were normalized to $18 \mathrm{~S}$ ribosomal RNA and are presented as relative quantification (RQ) values. All graphs show data from individual mice with lines showing mean \pm SEM Group sizes were $n=6$ mice per group. Statistically significant differences between groups were analyzed by one-way analysis of variance (ANOVA) with post hoc Tukey's test; ${ }^{*} P<0.05,{ }^{* *} P<0.01,{ }^{* * *} P<0.001$ and ${ }^{* * *} P<0.0001$

$(P<0.001)$. The degree of tryptophan depletion was less pronounced in $K m o^{\text {null }}$ mice than $K m o^{\text {wt }}$ mice after IRI, but this was not statistically significant between these two mouse strains (Fig. 6a). Kynurenine concentrations were not altered in IRI to an extent that exceeded the profound differences at baseline between $K m o^{\mathrm{wt}}$ and $K m o^{\text {null }}$ mouse strains (Fig. 6b). Experimental IRI caused an elevation in the potentially protective molecule kynurenic acid that was significantly further increased in $K m o^{\text {null }}$ mice with IRI $\left(K m o^{\text {null }}\right.$ IRI $8738.0 \pm 673.6 \mathrm{ng} / \mathrm{mL}$ and $K m o^{\mathrm{wt}}$ IRI $581.6 \pm 72.9 \mathrm{ng} / \mathrm{mL} ; P<0.0001$, Fig. 6c). Although IRI induced a rise in 3-hydroxyanthranilic acid, this was not different between $K m o^{\mathrm{wt}}$ and $K m o^{\text {null }}$ mouse strains $\left(K m o^{\text {null }}\right.$ IRI $324.3 \pm 93.6 \mathrm{ng} / \mathrm{mL}$ and $K m o^{\text {wt }}$ IRI $389.0 \pm 33.3 \mathrm{ng} / \mathrm{mL}$; Figure 6d). Concentrations of 3-hydroxykynurenine were significantly increased $24 \mathrm{~h}$ after IRI in $K m o^{\text {wt }}$ mice in plasma (IRI $53.3 \pm 6.3 \mathrm{ng} / \mathrm{mL}$ and sham $34.0 \pm 6.3 \mathrm{ng} / \mathrm{mL} ; P<0.05$, Fig. $6 \mathrm{e}$ ), but not in kidney tissue (Fig. 6f), and, as expected, $K m o^{\text {null }}$ mice showed extremely low levels of 3-hydroxykynurenine in plasma and KMO activity in kidney tissue (Figs. 6e, f). Together, these data convincingly demonstrate that 3hydroxykynurenine production by KMO is a significant contributor to AKI following renal IRI, and reinforce the concept of KMO inhibition as a protective strategy to protect against organ dysfunction in critical illness.

\section{Discussion}

Kynurenine metabolites are generated by tryptophan catabolism and regulate biological processes that include host-microbiome signaling, immune cell response, and neuronal excitability ${ }^{20}$. More recently, we and others are focusing on the role of the kynurenine pathway in inflammation and tissue injury. In particular, we have focused on the pathway enzyme KMO, which plays a key gate-keeper role in kynurenine metabolism, by determining the metabolic fate of kynurenine generated by upstream dioxygenases. Recent genetic analysis in mice identified $\mathrm{Kmo}$ as a candidate gene associated with albuminuria. Glomerular KMO expression is decreased in both mouse and human kidneys in a diabetic environment ${ }^{19}$. These previous reports support a link between $\mathrm{KMO}$ expression and healthy kidney function. In the present work, we conclusively demonstrate that KMO is a critical regulator of tissue injury in kidneys subjected to IRI. We used a transgenic mouse strain (Kmo null mice) that lacks KMO activity in all tissues by disruption of transcription in exon 5 of the Kmo gene, and compared it with $K m o^{\text {wt }}$ mice with normal KMO activity. The key finding of our paper is that $K m o^{\text {null }}$ mice are significantly protected from AKI after IRI, measured by preserved biochemical renal function and histological evidence of protection against tubule cell necrosis and apoptosis. Furthermore, neutrophil infiltration was reduced in $K m o^{\text {null }}$ mice with IRI, when compared with $K m o^{\text {wt }}$ mice as controls.

Tryptophan metabolism through the kynurenine pathway is most widely studied to date in relation to disorders of the nervous system, for example, Huntington's disease, stress-related depression, schizophrenia, Alzheimer's disease, and Parkinson's disease ${ }^{21}$. In recent years, the regulation of kynurenine metabolism has been increasingly evaluated in relation to acute tissue injury, and has become an attractive therapeutic target in several disease $\operatorname{areas}^{22}$. Our data here show altered kynurenine metabolite levels in $K m o^{\text {null }}$ mice after IRI compared with $K m o^{\text {wt }}$ IRI mice. Despite showing comparable downregulated expression of the kynurenine pathway enzymes following experimental IRI, levels of kynurenine and kynurenic acid were significantly higher in $K m o^{\text {null }}$ mice compared with $K m o^{\text {wt }}$ controls. Although such changes are characteristic of the $K m o^{\text {null }}$ phenotype, kynurenine and kynurenic acid levels were further increased in $K m o^{\text {null }}$ IRI mice compared with $K m o^{\text {null }}$ sham-operated mice. These metabolites may contribute to protection from AKI after IRI in $K m o^{\text {null }}$ mice, particularly since kynurenic acid has demonstrated a protective role in a number of other inflammatory situations through its activity at glutamate receptors. Levels of free radical-generating 3-hydroxyanthranalic acid were increased to a similar degree in both mouse strains following induction of IRI suggesting that this metabolite is not implicated in the development of AKI. As plasma 3HK production was significantly higher in $K m o^{\text {wt }}$ IRI mice than in all other conditions, it seems likely that $3 \mathrm{HK}$-mediated effects contribute to the observed exacerbated response to IRI. This study provides 

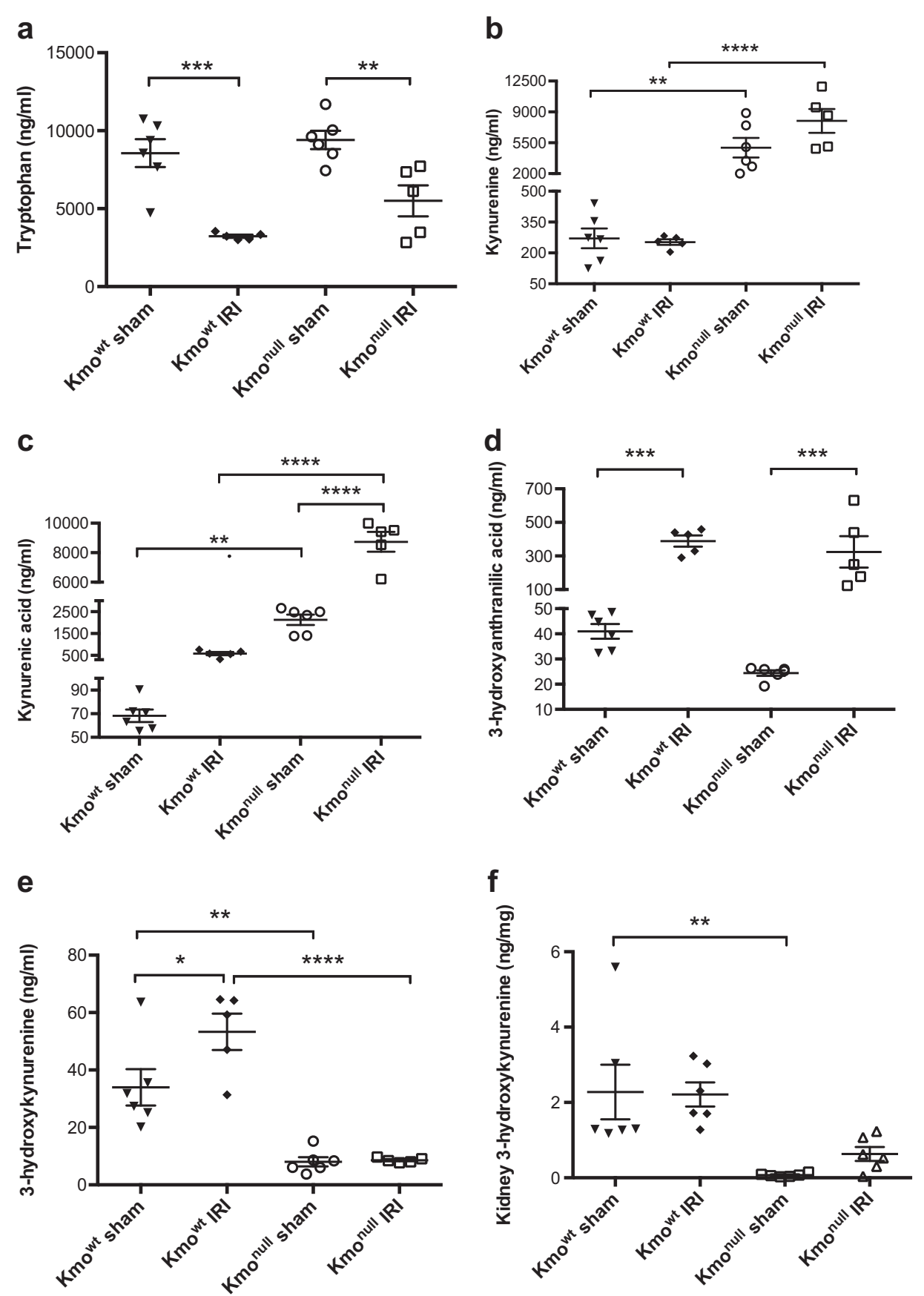

Fig. 6 Kynurenine pathway metabolite concentrations in plasma and kidney tissue after ischemia-reperfusion injury (IRI). a Plasma tryptophan; b plasma kynurenine; c plasma kynurenic acid; d plasma 3-hydroxyanthranilic acid; e plasma 3-hydroxykynurenine; $\mathbf{f}$ kidney tissue 3hydroxykynurenine. For all panels, mice were subjected to unilateral nephrectomy and contralateral IRI, or sham operation, under general anesthesia. Twenty-four hours after IRI or sham operation, mice were euthanased and blood and kidney tissue sampled for analysis. Extracts of plasma (panels a-e) or kynurenine 3-monooxygenase (KMO) activity in kidney tissue (panel f) were analyzed by liquid chromatography-tandem mass spectrometry (LC-MS/MS) as described. All graphs show data from individual mice (one data point per mouse), with lines showing mean \pm SEM. Group sizes were $n$ $=6$ or $n=5$ (where one plasma was not obtained) mice per group. Statistically significant differences between groups were analyzed by one-way analysis of variance (ANOVA) with post hoc Tukey's test; ${ }^{*} P<0.05$, ${ }^{* *} P<0.01,{ }^{* * *} P<0.001$ and ${ }^{* * * *} P<0.0001$

further evidence that metabolic flux through the kynurenine pathway is upregulated in systemic inflammation, congruent with clinical observations in humans with
$\mathrm{AP}^{23,24}$, trauma ${ }^{25,26}$, undergoing coronary artery bypass surgery $^{27}$, sepsis $^{28}$, and chronic renal failure ${ }^{29}$. Plasma concentrations of 3-hydroxykynurenine correlate with the 
burden of inflammation, incidence of organ dysfunction and AP severity in human ${ }^{24}$. Altered kynurenine pathway metabolite levels observed here suggest that KMO also plays a critical role in kidney injury, strengthening the rationale for the use of systemic KMO inhibitors in this indication.

$K m o^{\text {null }}$ mice were generated and characterized in our laboratory to investigate the role of 3-hyxdroxykynurenine as an important effector of tissue injury. In $K m o^{\text {null }}$ mice, fecundity, fertility, and longevity up to 2 years of age are not affected, from which we can infer that prolonged KMO blockade and consequent chronic exposure to significantly elevated concentrations of kynurenic acid and kynurenine is well tolerated, at least in adapted mice ${ }^{12}$. Other researchers have also independently demonstrated that the deleted Kmo was not essential for embryonic and postnatal survival ${ }^{30}$. Our finding that $K m o^{\text {null }}$ mice do not have albuminuria at baseline is contrary to a report from others ${ }^{19}$, but could possibly explained by difference in C57BL/6 substrain. The background strain used by Konstanje et al. ${ }^{19}$ was C57BL/6N and the background strain of our mice used in this article is C57BL/6J. Interestingly, deleting of arylformamidase (Afmid) in mice leads to a glomerulosclerosis phenotype. However, the Afmid mouse also has a thymidine kinase promoter deleted and a glucose intolerance phenotype with reduced insulin secretion and therefore is not a clean model from which a direct inference of an effect on kynurenine metabolism on renal function can be drawn ${ }^{31,32}$. KMO depletion decreased plasma $3 \mathrm{HK}$ level and increased plasma KA level, which may be potentially protective against renal damage caused by IRI.

Kidney IRI is an inevitable consequence of the procedure of kidney transplantation and its severity has been correlated with an increased incidence of both acute and chronic rejection ${ }^{17,33}$. Apoptosis of tubular epithelial cells contributes to the development of ischemic AKI, and injury at this site contributes to organ failure. Inhibiting apoptosis, both before and after renal insults, will inevitably improve the outcome of human $\mathrm{AKI}^{34}$. Neutrophils and monocytes/macrophages are important contributors to ischemic kidney injury and repair. Neutrophils attach to the activated endothelium and accumulate in the kidney both in animal models and in human $\mathrm{AKI}^{35}$. Recent studies have shown that pro-inflammatory cytokines and chemokines such as TNF- $\alpha$, IL- 6 , monocyte chemoattractant protein 1, and MIP-2 contribute to the development of renal IRI ${ }^{36}$. In the present study, we report the original finding that genetic KMO deletion provides protection against kidney damage caused by IRI. Renal injury was observed on histological sections of kidney tissue from mice with IRI. They also showed an increase in neutrophilic inflammation and increased apoptosis. All these features of renal injury were essentially reduced in KMO depletion mice. Additionally, we observed that the
mRNA expression of pro-inflammatory cytokines such as TNF- $\alpha$ and IL- 6 increased in IRI mice compared with sham animals, which has been reported earlier in human AP patients ${ }^{24}$. There was no significant difference about the TNF $\alpha$ and IL-6 mRNA expression between $K m o^{\text {null }}$ and $K m o^{\text {wt }}$ IRI mice. The chemokines $\mathrm{C}-\mathrm{X}-\mathrm{C}$ motif ligand 1 (CXCL1)/keratinocyte chemoattractant (KC), C-X-C motif ligand 2 (CXCL2)/macrophage inflammatory protein-2 (MIP-2) have been found to contribute to the pathology of a number of neutrophil-dependent animal models of disease, including IRI ${ }^{37-39}$. Our study showed that renal CXCL1 and CXCL2 mRNA expression were upregulated in IRI $K m o^{\text {wt }}$ mice compared with shamoperated control mice. Lower CXCL2 mRNA levels in $K m o^{\text {null }}$ IRI mice compared with $K m o^{\text {wt }}$ IRI mice are consistent with our observation of reduced neutrophil infiltration.

In summary, our study shows $K m o^{\text {null }}$ mice had preserved renal function, reduced renal tubule cell injury and apoptosis, and fewer infiltrating neutrophils compared with $K m o^{\text {wt }}$ control mice. Together, these data strongly support the translational potential of KMO inhibition as a therapeutic strategy to protect against renal injury in acute inflammation.

\section{Acknowledgements}

We thank Spike Clay, Gary Borthwick, all members of the Biological Research Facility; Forbes Howie; Paul Fitch; Melanie McMillian, Debbie Mauchline, and the SURF Facility; for their invaluable technical and/or management assistance. This work was supported by a Clinician Scientist Fellowship from the Health Foundation/Academy of Medical Sciences to D.J.M. D.J.M. now acknowledges the support of the MRC through a Senior Clinical Fellowship.

\section{Authors' contributions}

Conceptualization: X.Z. and D.J.M. Methodology: X.Z., A.Z., M.B., K.M., and D.J.M. Investigation: X.Z., A.Z., M.B., and D.J.M. Writing - original draft: X.Z. and D.J.M. Writing-review and editing: X.Z., K.M., S.P.W., J.H., S.E.M.H., and D.J.M. Funding acquisition: D.J.M. Supervision: D.J.M., X.Z., S.P.W., and S.E.M.H. All authors read, discussed, and agreed with the final version of this manuscript.

Conflict of interest

The authors declare that they have no conflict of interest.

\section{Publisher's note}

Springer Nature remains neutral with regard to jurisdictional claims in published maps and institutional affiliations.

Supplementary information accompanies this paper at https://doi.org/ 10.1038/s12276-019-0210-x.

Received: 29 July 2018 Revised: 18 October 2018 Accepted: 13 November 2018.

Published online: 13 February 2019

\footnotetext{
References

1. Stone, T. W. \& Darlington, L. G. Endogenous kynurenines as targets for drug discovery and development. Nat. Rev. Drug. Discov. 1, 609-620 (2002).

2. Consortium, T. M. et al. Single-cell transcriptomics of 20 mouse organs creates a Tabula Muris. Nature 562, 367-372 (2018).
} 
3. Thul, P. J. \& Lindskog, C. The human protein atlas: a spatial map of the human proteome. Protein Sci. 27, 233-244 (2018).

4. Nakagami, Y., Saito, H. \& Katsuki, H. 3-Hydroxykynurenine toxicity on the rat striatum in vivo. Jpn. J. Pharmacol. 71, 183-186 (1996).

5. Mizdrak, J., Hains, P. G., Truscott, R. J., Jamie, J. F. \& Davies, M. J. Tryptophanderived ultraviolet filter compounds covalently bound to lens proteins are photosensitizers of oxidative damage. Free Radic. Biol. Med. 44, 1108-1119 (2008).

6. Wang, Q. X. et al. Activation of NAD (P) H oxidase by tryptophan-derived 3hydroxykynurenine accelerates endothelial apoptosis and dysfunction in vivo. Circ. Res. 114, 480-492 (2014).

7. Wilson, K. et al. Overexpression of human kynurenine-3-monooxygenase protects against 3-hydroxykynurenine-mediated apoptosis through bidirectional nonlinear feedback. Cell Death Dis. 7, e2197 (2016).

8. Harris, C. A. et al. Modulation of striatal quinolinate neurotoxicity by elevation of endogenous brain kynurenic acid. Br. J. Pharmacol. 124, 391-399 (1998).

9. Beninger, R. J., Jhamandas, K, Boegman, R. J. \& el-Defrawy, S. R. Kynurenic acidinduced protection of neurochemical and behavioural deficits produced by quinolinic acid injections into the nucleus basalis of rats. Neurosci. Lett. $\mathbf{6 8}$ 317-321 (1986).

10. Vecsei, L., Szalardy, L., Fulop, F. \& Toldi, J. Kynurenines in the CNS: recent advances and new questions. Nat. Rev. Drug. Discov. 12, 64-82 (2013).

11. Mole, D. J., Olabi, B., Robinson, V., Garden, O. J. \& Parks, R. W. Incidence of individual organ dysfunction in fatal acute pancreatitis: analysis of 1024 death records. Hpb. (Oxf.). 11, 166-170 (2009).

12. Mole, D. J. et al. Kynurenine-3-monooxygenase inhibition prevents multiple organ failure in rodent models of acute pancreatitis. Nat. Med. 22, 202-209 (2016).

13. Hutchinson, J. P. et al. Structural and mechanistic basis of differentiated inhibitors of the acute pancreatitis target kynurenine-3-monooxygenase. Nat. Commun. 8, 15827 (2017).

14. Liddle, J. et al. The discovery of potent and selective kynurenine 3monooxygenase inhibitors for the treatment of acute pancreatitis. Bioorg. Med. Chem. Lett. 27, 2023-2028 (2017).

15. Walker, A. L. et al. Development of a series of kynurenine 3-monooxygenase inhibitors leading to a clinical candidate for the treatment of acute pancreatitis. J. Med. Chem. 60, 3383-3404 (2017).

16. Hesketh, E. E. et al. Renal ischaemia reperfusion injury: a mouse model of injury and regeneration. J Visual. Exp. https://doi.org/10.3791/51816 (2014).

17. $\mathrm{Wu}, \mathrm{H}$. et al. Preconditioning with recombinant high-mobility group box 1 protein protects the kidney against ischemia-reperfusion injury in mice. Kid. Int. 85, 824-832 (2014).

18. Faul, F., Erdfelder, E., Lang, A. G. \& Buchner, A. G*Power 3: a flexible statistical power analysis program for the social, behavioral, and biomedical sciences. Behav. Res. Methods 39, 175-191 (2007).

19. Korstanje, R. et al. Loss of kynurenine 3-mono-oxygenase causes proteinuria. J Am. Soc. Nephrol. 27, 3271-3277 (2016).

20. Cervenka, I., Agudelo, L. Z. \& Ruas, J. L. Kynurenines: tryptophan's metabolites in exercise, inflammation, and mental health. Science. 357, eaaf9794 (2017). https:/doi.org/10.1126/science.aaf9794
21. Schwarcz, R. \& Stone, T. W. The kynurenine pathway and the brain: challenges, controversies and promises. Neuropharmacology 112, 237-247 (2017).

22. Thevandavakkam, M. A., Schwarcz, R., Muchowski, P. J. \& Giorgini, F. Targeting kynurenine 3-monooxygenase (KMO): implications for therapy in Huntington's disease. CNS Neurol. Disord. Drug Targets 9, 791-800 (2010).

23. Mole, D. J. et al. Tryptophan catabolites in mesenteric lymph may contribute to pancreatitis-associated organ failure. Br. J. Surg. 95, 855-867 (2008).

24. Skouras, C. et al. Increased levels of 3-hydroxykynurenine parallel disease severity in human acute pancreatitis. Sci. Rep. 6, 33951 (2016).

25. Logters, T. T. et al. Increased plasma kynurenine values and kynureninetryptophan ratios after major trauma are early indicators for the development of sepsis. Shock 32, 29-34 (2009).

26. Pellegrin, $\mathrm{K}$. et al. Enhanced enzymatic degradation of tryptophan by indoleamine 2,3-dioxygenase contributes to the tryptophan-deficient state seen after major trauma. Shock 23, 209-215 (2005).

27. Forrest, C. M. et al. Kynurenine metabolism predicts cognitive function in patients following cardiac bypass and thoracic surgery. J. Neurochem. 119, 136-152 (2011).

28. Wang, Y. et al. Kynurenine is an endothelium-derived relaxing factor produced during inflammation. Nat. Med. 16, 279-285 (2010).

29. Pawlak, K., Domaniewski, T., Mysliwiec, M. \& Pawlak, D. The kynurenines are associated with oxidative stress, inflammation and the prevalence of cardiovascular disease in patients with end-stage renal disease. Atherosclerosis 204, 309-314 (2009).

30. Giorgini, F. et al. Targeted deletion of kynurenine 3-monooxygenase in mice: a new tool for studying kynurenine pathway metabolism in periphery and brain. J. Biol. Chem. 288, 36554-36566 (2013).

31. Dobrovolsky, V. N. et al. Effect of arylformamidase (kynurenine formamidase) gene inactivation in mice on enzymatic activity, kynurenine pathway metabolites and phenotype. Biochim. Biophys. Acta 1724, 163-172 (2005).

32. Hugill, A. J. et al. Loss of arylformamidase with reduced thymidine kinase expression leads to impaired glucose tolerance. Biol. Open 4, 1367-1375 (2015).

33. Nankivell, B. J. \& Alexander, S. I. Rejection of the kidney allograft. N. Engl. J. Med. 363, 1451-1462 (2010).

34. Havasi, A. \& Borkan, S. C. Apoptosis and acute kidney injury. Kid. Int. 80, 29-40 (2011).

35. Bonventre, J. V. \& Yang, L. Cellular pathophysiology of ischemic acute kidney injury. J. Clin. Inv. 121, 4210-4221 (2011).

36. Zhou, J., Jia, L., Hu, Z. \& Wang, Y. Pharmacological inhibition of PTEN aggravates acute kidney injury. Sci. Rep. 7, 9503 (2017).

37. Miura, M., Fu, X., Zhang, Q. W., Remick, D. G. \& Fairchild, R. L. Neutralization of Gro alpha and macrophage inflammatory protein-2 attenuates renal ischemia/reperfusion injury. Am. J. Pathol. 159, 2137-2145 (2001).

38. Souza, D. G. et al. Repertaxin, a novel inhibitor of rat CXCR2 function, inhibits inflammatory responses that follow intestinal ischaemia and reperfusion injury. Br. J. Pharmacol. 143, 132-142 (2004).

39. Belperio, J. A. et al. CXCR2/CXCR2 ligand biology during lung transplant ischemia-reperfusion injury. J. Immunol. 175, 6931-6939 (2005). 